\title{
Retailer's Optimal Pricing and Ordering Policies for Non-Instantaneous Deteriorating Items with Price-Dependent Demand and Partial Backlogging
}

\author{
Chih-Te Yang, ${ }^{1}$ Liang-Yuh Ouyang, ${ }^{2}$ and Hsing-Han $\mathrm{Wu}^{3}$ \\ ${ }^{1}$ Department of Industrial Engineering \& Management, Ching Yun University, Jung-Li, \\ Taoyuan 320, Taiwan \\ ${ }^{2}$ Department of Management Sciences and Decision Making, Tamkang University, Tamsui, \\ Taipei 251, Taiwan \\ ${ }^{3}$ Graduate Institute of Management Sciences, Tamkang University, Tamsui, Taipei 251, Taiwan
}

Correspondence should be addressed to Chih-Te Yang, ctyang@cyu.edu.tw

Received 27 December 2008; Revised 22 June 2009; Accepted 19 August 2009

Recommended by Wei-Chiang Hong

\begin{abstract}
An inventory system for non-instantaneous deteriorating items with price-dependent demand is formulated and solved. A model is developed in which shortages are allowed and partially backlogged, where the backlogging rate is variable and dependent on the waiting time for the next replenishment. The major objective is to determine the optimal selling price, the length of time in which there is no inventory shortage, and the replenishment cycle time simultaneously such that the total profit per unit time has a maximum value. An algorithm is developed to find the optimal solution, and numerical examples are provided to illustrate the theoretical results. A sensitivity analysis of the optimal solution with respect to major parameters is also carried out.
\end{abstract}

Copyright (C) 2009 Chih-Te Yang et al. This is an open access article distributed under the Creative Commons Attribution License, which permits unrestricted use, distribution, and reproduction in any medium, provided the original work is properly cited.

\section{Introduction}

The Economic Order Quantity (EOQ) model proposed by Harris [1] has been widely used by enterprises in order to reduce the cost of stock. Due to the variability in economic circumstances, many scholars constantly modify the basic assumptions of the EOQ model and consider more realistic factors in order to make the model correspond with reality. One such modification is the inclusion of the deterioration of items. In general, deterioration is defined as damage, spoilage, dryness, vaporization, and so forth, which results in a decrease of the usefulness of the original item. Ghare and Schrader [2] were the first to consider deterioration when they presented an EOQ model for an exponentially constant deteriorating inventory. Later, Covert and Philip [3] formulated the model with a variable deterioration rate with a 
two-parameter Weibull distribution. Philip [4] then developed the inventory model with a three-parameter Weibull distribution rate and no shortages. Tadikamalla [5] further developed the inventory model with deterioration using Gamma distribution. Shah [6] extended Philip's [4] model by allowing shortages and complete backlogging. However, when shortages occur, one cannot be certain that customers are willing to wait for a backorder. Some customers are willing to wait, while others will opt to buy from other sellers. Park [7] and Wee [8] considered constant partial backlogging rates during a shortage period in their inventory models. In some instances the backlogging rate was variable. Abad $[9,10]$ investigated EOQ models for deteriorating items allowing shortage and partial backlogging. He assumed that the backlogging rate was variable and dependent on the length of waiting time for the next replenishment. Two backlogging rates which are dependent on the length of waiting time for the next replenishment arose: $k_{0} e^{-\delta x}$ and $k_{0} /(1+\delta x)$, where $x$ is the length of waiting time for the next replenishment, $0<k_{0} \leq 1$ and $\delta>0$. Dye [11] revised Abad's [10] model by adding both the backorder cost and the cost of lost sales to the total profit function. There is a vast amount of literature on inventory models for deteriorating items. Review articles by Goyal [12], Sarma [13], Raafat et al. [14], Pakkala and Achary [15], Goyal and Giri [16], Ouyang et al. [17], Dye et al. [18], and others provide a summary of this material. In this literature, all the inventory models for deteriorating items assume that the deterioration of inventory items starts as soon as they arrive in stock. However, in real life most goods would have an initial period in which the quality or original condition is maintained, namely, no deterioration occurs. This type of phenomenon is common, for example, firsthand fruit and vegetables have a short span during which fresh quality is maintained and there is almost no spoilage. $\mathrm{Wu}$ et al. [19] defined a phenomenon of "non-instantaneous deterioration" and developed a replenishment policy for non-instantaneous deteriorating items with stock-dependent demand such that the total relevant inventory cost per unit time had a minimum value.

In addition to deterioration, price has a great impact on demand. In general, a decrease in selling price leads to increased customer demand and results in a high sales volume. Therefore, pricing strategy is a primary tool that sellers or retailers use to maximize profit and consequently models with price-dependent demand occupy a prominent place in the inventory literature. Eilon and Mallaya [20] were the first to investigate a deteriorating inventory model with price-dependent demand. Cohen [21] determined both the optimal replenishment cycle and price for inventory that was subject to continuous decay over time at a constant rate. Wee [22] studied pricing and replenishment policy for a deteriorating inventory with a price elastic demand rate that declined over time. Abad [9] considered the dynamic pricing and lot sizing problem of a perishable good under partial backlogging of demand. He assumed that the fraction of shortages backordered was variable and a decreasing function of the waiting time. Wee [23, 24] extended Cohen's [21] model to develop a replenishment policy for deteriorating items with price-dependent demand, with Weibull distribution deterioration and separately considered with/without a quantity discount. Wee and Law [25] developed an inventory model for deteriorating items with price-dependent demand in which the time value of money was also taken into account. Abad [26] presented a model of pricing and lot sizing under conditions of perishability, finite production, and partial backlogging. Mukhopadhyay et al. [27, 28] re-established Cohen's [21] model by taking a price elastic demand rate and considering a time-proportional and two-parameter Weibull distribution deterioration rate separately. Chang et al. [29] introduced a deteriorating inventory model with price-time dependent demand and partial backlogging.

In order to match realistic circumstances, a non-instantaneous deteriorating inventory model for determining the optimal pricing and ordering policies with price-dependent 
demand is considered in this study. In the model, shortages are allowed and partially backlogged where the backlogging rate is variable and dependent on the waiting time for the next replenishment. The purpose is to simultaneously determine the optimal selling price, the length of time in which there is no inventory shortage, and the replenishment cycle time, such that the total profit per unit time has a maximum value for the retailer. There are two possible scenarios in this study. The length of time in which there is no shortage is (i) larger than or equal to, or (ii) shorter than or equal to the length of time in which the product has no deterioration. The optimal pricing and ordering policies are obtained through theoretical analysis. It is first proven that for any given selling price, the optimal values of the length of time in which there is no inventory shortage and the replenishment cycle time not only exist, but are unique. Next, this paper proves that there exists a unique selling price to maximize the total profit per unit time when the time in which there is no inventory shortage and the replenishment cycle time are given. Furthermore, an algorithm is developed to find the optimal solution. Numerical examples are provided to illustrate the theoretical results and a sensitivity analysis of the optimal solution with respect to major parameters is also carried out.

\section{Notation and Assumptions}

The following notation and assumptions are used throughout the paper.

Notation. A: The ordering cost per order

$c$ : The purchasing cost per unit

$c_{1}$ : The holding cost per unit per unit time

$c_{2}$ : The shortage cost per unit per unit time

$c_{3}$ : The unit cost of lost sales

$p$ : The selling price per unit, where $p>c$

$\theta$ : The parameter of the deterioration rate function

$t_{d}$ : The length of time in which the product exhibits no deterioration

$t_{1}$ : The length of time in which there is no inventory shortage

$T$ : The length of the replenishment cycle time

$Q$ : The order quantity

$p^{*}$ : The optimal selling price per unit

$t_{1}^{*}$ : The optimal length of time in which there is no inventory shortage

$T^{*}$ : The optimal length of the replenishment cycle time

$Q^{*}$ : The optimal order quantity

$I_{1}(t)$ : The inventory level at time $t \in\left[0, t_{d}\right]$

$I_{2}(t)$ : The inventory level at time $t \in\left[t_{d}, t_{1}\right]$, where $t_{1}>t_{d}$

$I_{3}(t)$ : The inventory level at time $t \in\left[t_{1}, T\right]$

$I_{0}$ : The maximum inventory level

$S$ : The maximum amount of demand backlogged

$T P\left(p, t_{1} T\right)$ : The total profit per unit time of the inventory system

$T P^{*}$ : The optimal total profit per unit time of the inventory system, that is, $T P^{*}=$ $T P\left(p^{*}, t_{1}^{*}, T^{*}\right)$. 


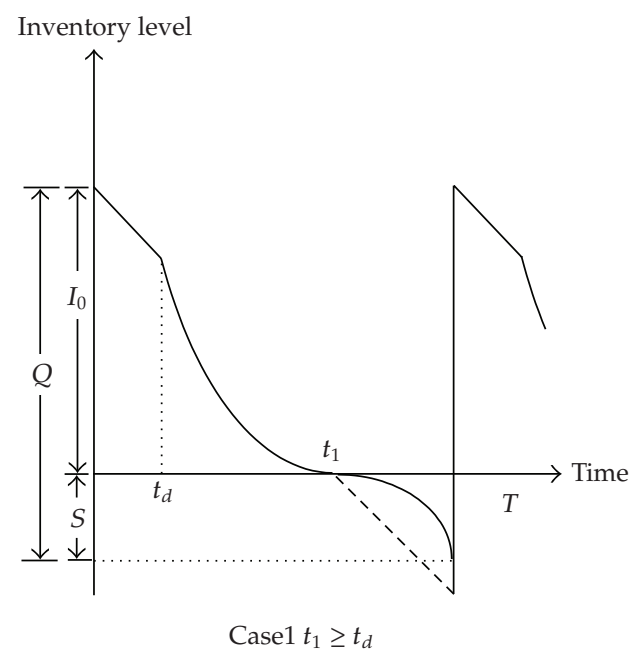

(a)



(b)

Figure 1: Graphical representation of inventory system.

Assumptions. (1) A single non-instantaneous deteriorating item is modeled.

(2) The replenishment rate is infinite and the lead time is zero.

(3) The demand rate $D(p)$ is a non-negative, continuous, decreasing, and concave function of the selling price $p$, that is, $D^{\prime}(p)<0$ and $D^{\prime \prime}(p)<0$.

(4) During the fixed period, $t_{d}$, there is no deterioration and at the end of this period, the inventory item deteriorates at the constant rate $\theta$.

(5) There is no replacement or repair for deteriorated items during the period under consideration.

(6) Shortages are allowed to occur. It is assumed that only a fraction of demand is backlogged. Furthermore the longer the waiting time, the smaller the backlogging rate. Let $B(x)$ denote the backlogging rate given by $B(x)=1 /(1+\delta x)$, where $x$ is the waiting time until the next replenishment and $\delta$ is a positive backlogging parameter.

\section{Model Formulation}

First a short problem description is provided. The replenishment problem of a single noninstantaneous deteriorating item with partial backlogging is considered in this study. The inventory system is as follows. $I_{0}$ units of item arrive at the inventory system at the beginning of each cycle and drop to zero due to demand and deterioration. Then shortage occurs until the end of the current order cycle. Based on the values of $t_{1}$ and $t_{d}$, there are two possible cases: (1) $t_{1} \geq t_{d}$ and (2) $t_{1} \leq t_{d}$ (see Figure 1). These cases are discussed as follows.

Case $1\left(t_{1} \geq t_{d}\right)$. In this case, the length of time in which there is no shortage is larger than or equal to the length of time in which the product has no deterioration. During the time interval $\left[0, t_{d}\right]$, the inventory level decreases due to demand only. Subsequently the inventory level 
drops to zero due to both demand and deterioration during the time interval $\left[t_{d}, t_{1}\right]$. Finally, a shortage occurs due to demand and partial backlogging during the time interval $\left[t_{1}, T\right]$. The whole process is repeated.

As described before, the inventory level decreases according to demand only during the time interval $\left[0, t_{d}\right]$. Hence the differential equation representing the inventory status is given by

$$
\frac{d I_{1}(t)}{d t}=-D(p), \quad 0<t<t_{d}
$$

with the boundary condition $I_{1}(0)=I_{0}$. By solving (3.1) over time $t$, it yields.

$$
I_{1}(t)=I_{0}-D(p) t, \quad 0 \leq t \leq t_{d}
$$

During the time interval $\left[t_{d}, t_{1}\right]$, the inventory level decreases due to demand as well as deterioration. Thus, the differential equation representing the inventory status is given by

$$
\frac{d I_{2}(t)}{d t}+\theta I_{2}(t)=-D(p), \quad t_{d}<t<t_{1}
$$

with the boundary condition $I_{2}\left(t_{1}\right)=0$. The solution of (3.3) is

$$
I_{2}(t)=\frac{D(p)}{\theta}\left[e^{\theta\left(t_{1}-t\right)}-1\right], \quad t_{d} \leq t \leq t_{1} .
$$

Considering continuity of $I_{1}(t)$ and $I_{2}(t)$ at point $t=t_{d}$, that is, $I_{1}\left(t_{d}\right)=I_{2}\left(t_{d}\right)$, the maximum inventory level for each cycle can be obtained and is given by

$$
I_{0}=\frac{D(p)}{\theta}\left[e^{\theta\left(t_{1}-t_{d}\right)}-1\right]+D(p) t_{d}
$$

Substituting (3.5) into (3.2) gives

$$
I_{1}(t)=\frac{D(p)}{\theta}\left[e^{\theta\left(t_{1}-t_{d}\right)}-1\right]+D(p)\left(t_{d}-t\right), \quad 0 \leq t \leq t_{d}
$$

During the shortage time interval $\left[t_{1}, T\right]$, the demand at time $t$ is partially backlogged according to the fraction $B(T-t)$. Thus, the inventory level at time $t$ is governed by the following differential equation:

$$
\frac{d I_{3}(t)}{d t}=-D(p) B(T-t)=\frac{-D(p)}{1+\delta(T-t)}, \quad t_{1}<t<T,
$$

with the boundary condition $I_{3}\left(t_{1}\right)=0$. The solution of (3.7) is

$$
I_{3}(t)=\frac{-D(p)}{\delta}\left\{\ln \left[1+\delta\left(T-t_{1}\right)\right]-\ln [1+\delta(T-t)]\right\}, \quad t_{1} \leq t \leq T .
$$


Putting $t=T$ into (3.8), the maximum amount of demand backlogged per cycle is obtained as follows:

$$
S \equiv-I_{3}(T)=\frac{D(p)}{\delta} \ln \left[1+\delta\left(T-t_{1}\right)\right]
$$

From (3.5) and (3.9), one can obtain the order quantity per cycle as

$$
Q=I_{0}+S=\frac{D(p)}{\theta}\left[e^{\theta\left(t_{1}-t_{d}\right)}-1\right]+D(p) t_{d}+\frac{D(p)}{\delta} \ln \left[1+\delta\left(T-t_{1}\right)\right]
$$

Next, the total relevant inventory cost and sales revenue per cycle consist of the following six elements.

(a) The ordering cost is $A$.

(b) The inventory holding cost (denoted by $H C$ ) is

$$
\begin{aligned}
H C & =c_{1}\left[\int_{0}^{t_{d}} I_{1}(t) d t+\int_{t_{d}}^{t_{1}} I_{2}(t) d t\right] \\
& =c_{1}\left\{\int_{0}^{t_{d}}\left\{\frac{D(p)}{\theta}\left[e^{\theta\left(t_{1}-t_{d}\right)}-1\right]+D(p)\left(t_{d}-t\right)\right\} d t+\int_{t_{d}}^{t_{1}} \frac{D(p)}{\theta}\left[e^{\theta\left(t_{1}-t\right)}-1\right] d t\right\} \\
& =c_{1} D(p)\left\{\frac{t_{d}}{\theta}\left[e^{\theta\left(t_{1}-t_{d}\right)}-1\right]+\frac{t_{d}^{2}}{2}+\frac{1}{\theta^{2}}\left[e^{\theta\left(t_{1}-t_{d}\right)}-\theta\left(t_{1}-t_{d}\right)-1\right]\right\}
\end{aligned}
$$

(c) The shortage cost due to backlog (denoted by SC) is

$$
\begin{aligned}
S C & =c_{2} \int_{t_{1}}^{T}\left[-I_{3}(t)\right] d t=\frac{c_{2} D(p)}{\delta} \int_{t_{1}}^{T}\left\{\ln \left[1+\delta\left(T-t_{1}\right)\right]-\ln [1+\delta(T-t)]\right\} d t \\
& =\frac{c_{2} D(p)}{\delta}\left\{T-t_{1}-\frac{\ln \left[1+\delta\left(T-t_{1}\right)\right]}{\delta}\right\} .
\end{aligned}
$$

(d) The opportunity cost due to lost sales (denoted by OC) is

$$
\begin{aligned}
O C & =c_{3} \int_{t_{1}}^{T} D(p)[1-B(T-t)] d t=c_{3} \int_{t_{1}}^{T} D(p)\left[1-\frac{1}{1+\delta(T-t)}\right] d t \\
& =c_{3} D(p)\left\{T-t_{1}-\frac{\ln \left[1+\delta\left(T-t_{1}\right)\right]}{\delta}\right\} .
\end{aligned}
$$

(e) The purchase cost (denoted by PC) is

$$
P C=c Q=c D(p)\left\{\frac{1}{\theta}\left[e^{\theta\left(t_{1}-t_{d}\right)}-1\right]+t_{d}+\frac{1}{\delta} \ln \left[1+\delta\left(T-t_{1}\right)\right]\right\}
$$


(f) The sales revenue (denoted by $S R$ ) is

$$
S R=p\left[\int_{0}^{t_{1}} D(p) d t-I_{3}(T)\right]=p D(p)\left\{t_{1}+\frac{1}{\delta} \ln \left[1+\delta\left(T-t_{1}\right)\right]\right\} .
$$

Therefore, the total profit per unit time of Case 1 (denoted by $T P_{1}\left(p, t_{1}, T\right)$ ) is given by

$$
\begin{aligned}
T P_{1}\left(p, t_{1}, T\right)= & \frac{(S R-A-H C-S C-O C-P C)}{T} \\
=\frac{D(p)}{T}\{ & \left(p-c+\frac{c_{2}+\delta c_{3}}{\delta}\right)\left[t_{1}+\frac{\ln \left[1+\delta\left(T-t_{1}\right)\right]}{\delta}\right]-\frac{\theta\left(c+c_{1} t_{d}\right)+c_{1}}{\theta^{2}} \\
& \left.\times\left[e^{\theta\left(t_{1}-t_{d}\right)}-\theta\left(t_{1}-t_{d}\right)-1\right]-c_{1} t_{d} t_{1}+\frac{c_{1} t_{d}^{2}}{2}-\frac{c_{2}+\delta c_{3}}{\delta} T-\frac{A}{D(p)}\right\} .
\end{aligned}
$$

Case $2\left(t_{1} \leq t_{d}\right)$. In this case, the length of time in which there is no shortage is shorter than or equal to the length of time in which the product exhibits no deterioration. This implies that the optimal replenishment policy for the retailer is to sell out all stock before the deadline at which the items start to decay. Under these circumstances, the model becomes the traditional inventory model with a shortage. By using similar arguments as in Case 1, the order quantity per order, $Q$, and the total profit per unit time (denoted by $T P_{2}\left(p, t_{1}, T\right)$ ) can be obtained and are given by

$$
\begin{aligned}
& Q=D(p) t_{1}+\frac{D(p)}{\delta} \ln \left[1+\delta\left(T-t_{1}\right)\right] \\
& T P_{2}\left(p, t_{1}, T\right)=\frac{D(p)}{T}\left\{(p-c)\left[t_{1}+\frac{\ln \left[1+\delta\left(T-t_{1}\right)\right]}{\delta}\right]-\frac{c_{1} t_{1}^{2}}{2}\right. \\
&\left.-\frac{c_{2}+\delta c_{3}}{\delta}\left[T-t_{1}-\frac{\ln \left[1+\delta\left(T-t_{1}\right)\right]}{\delta}\right]-\frac{A}{D(p)}\right\} .
\end{aligned}
$$

Summarizing the above discussion, the total profit per unit time of the inventory system is as follows:

$$
T P\left(p, t_{1}, T\right)= \begin{cases}T P_{1}\left(p, t_{1}, T\right), & \text { if } t_{1} \geq t_{d} \\ T P_{2}\left(p, t_{1}, T\right), & \text { if } t_{1} \leq t_{d}\end{cases}
$$

where $T P_{1}\left(p, t_{1}, T\right)$ and $T P_{2}\left(p, t_{1}, T\right)$ are given by (3.16) and (3.18), respectively. Note that $T P_{1}\left(p, t_{1}, T\right)=T P_{2}\left(p, t_{1}, T\right)$ when $t_{1}=t_{d}$. Furthermore, for any solution $\left(p, t_{1}, T\right)$, the total 
profit per unit time $T P_{1}\left(p, t_{1}, T\right)$ and $T P_{2}\left(p, t_{1}, T\right)$ must be positive. If this set of criteria is not satisfied, the inventory system should not be operated because it is unprofitable. That is,

$$
\begin{gathered}
\left(p-c+\frac{c_{2}+\delta c_{3}}{\delta}\right)\left[t_{1}+\frac{\ln \left[1+\delta\left(T-t_{1}\right)\right]}{\delta}\right]-\frac{\theta\left(c+c_{1} t_{d}\right)+c_{1}}{\theta^{2}}\left[e^{\theta\left(t_{1}-t_{d}\right)}-\theta\left(t_{1}-t_{d}\right)-1\right] \\
-c_{1} t_{d} t_{1}+\frac{c_{1} t_{d}^{2}}{2}-\frac{c_{2}+\delta c_{3}}{\delta} T-\frac{A}{D(p)}>0, \quad \text { for } t_{1} \geq t_{d} \\
\left(p-c+\frac{c_{2}+\delta c_{3}}{\delta}\right)\left[t_{1}+\frac{\ln \left[1+\delta\left(T-t_{1}\right)\right]}{\delta}\right]-\frac{c_{1} t_{1}^{2}}{2}-\frac{c_{2}+\delta c_{3}}{\delta} T-\frac{A}{D(p)}>0, \quad \text { for } t_{1}<t_{d}
\end{gathered}
$$

\section{Theoretical Results}

The objective of this study is to determine the optimal pricing and ordering policies that correspond to maximizing the total profit per unit time. The problem is solved by using the following search procedure. It is first proven that for any given $p$, the optimal solution of $\left(t_{1}\right.$, $T$ ) not only exists but also is unique. Next for any given value of $\left(t_{1}, T\right)$, there exists a unique $p$ that maximizes the total profit per unit time. The detailed solution procedures for two cases are as follows.

Case $1\left(t_{1} \geq t_{d}\right)$. First, for any given $p$, the necessary conditions for the total profit per unit time in (3.16) to be maximized are $\partial T P_{1}\left(p, t_{1}, T\right) / \partial t_{1}=0$ and $\partial T P_{1}\left(p, t_{1}, T\right) / \partial T=0$ simultaneously. That is,

$$
\begin{gathered}
\frac{D(p)}{T}\left\{\left[(p-c)+\frac{c_{2}+\delta c_{3}}{\delta}\right] \frac{\delta\left(T-t_{1}\right)}{1+\delta\left(T-t_{1}\right)}-\frac{\theta\left(c+c_{1} t_{d}\right)+c_{1}}{\theta}\left[e^{\theta\left(t_{1}-t_{d}\right)}-1\right]-c_{1} t_{d}\right\}=0, \\
\frac{D(p)}{T^{2}}\left\{\left[(p-c)+\frac{c_{2}+\delta c_{3}}{\delta}\right]\left\{\frac{T}{1+\delta\left(T-t_{1}\right)}-t_{1}-\frac{\ln \left[1+\delta\left(T-t_{1}\right)\right]}{\delta}\right\}\right. \\
\left.+\frac{\theta\left(c+c_{1} t_{d}\right)+c_{1}}{\theta^{2}}\left[e^{\theta\left(t_{1}-t_{d}\right)}-\theta\left(t_{1}-t_{d}\right)-1\right]+c_{1} t_{d} t_{1}-\frac{c_{1} t_{d}^{2}}{2}+\frac{A}{D(p)}\right\}=0 .
\end{gathered}
$$

For notational convenience, let

$$
M \equiv \frac{c_{2}+\delta c_{3}}{\delta}>0, \quad N \equiv \frac{\theta\left(c+c_{1} t_{d}\right)+c_{1}}{\theta}>0
$$

Then, from (4.1), it can be found that

$$
T=t_{1}+\frac{N\left[e^{\theta\left(t_{1}-t_{d}\right)}-1\right]+c_{1} t_{d}}{\delta\left\{p-c+M-N\left[e^{\theta\left(t_{1}-t_{d}\right)}-1\right]-c_{1} t_{d}\right\}},
$$


Mathematical Problems in Engineering

$$
\begin{aligned}
& (p-c+M)\left\{\frac{T}{1+\delta\left(T-t_{1}\right)}-t_{1}-\frac{\ln \left[1+\delta\left(T-t_{1}\right)\right]}{\delta}\right\}+\frac{N}{\theta}\left[e^{\theta\left(t_{1}-t_{d}\right)}-\theta\left(t_{1}-t_{d}\right)-1\right] \\
& +c_{1} t_{d} t_{1}-\frac{c_{1} t_{d}^{2}}{2}+\frac{A}{D(p)}=0,
\end{aligned}
$$

respectively.

Due to $T>t_{1}$, from (4.3), it can be found that

$$
\frac{N\left[e^{\theta\left(t_{1}-t_{d}\right)}-1\right]+c_{1} t_{d}}{\delta\left\{p-c+M-N\left[e^{\theta\left(t_{1}-t_{d}\right)}-1\right]-c_{1} t_{d}\right\}}>0 .
$$

Because the numerator part $N\left[e^{\theta\left(t_{1}-t_{d}\right)}-1\right]+c_{1} t_{d}>0$, the denominator part $\delta\{p-c+M-$ $\left.N\left[e^{\theta\left(t_{1}-t_{d}\right)}-1\right]-c_{1} t_{d}\right\}>0$, or equivalently, $p-c+M-N\left[e^{\theta\left(t_{1}-t_{d}\right)}-1\right]-c_{1} t_{d}>0$, which implies $t_{1}<t_{d}+(1 / \theta) \ln \left[\left(p-c+M+N-c_{1} t_{d}\right) / N\right] \equiv t_{1}^{b}$. Substituting (4.3) into (4.4) and simplifying gives

$$
\begin{aligned}
& \left\{N\left[e^{\theta\left(t_{1}-t_{d}\right)}-1\right]+c_{1} t_{d}\right\}\left(\frac{1}{\delta}-t_{1}\right)-\frac{(p-c+M)}{\delta} \ln \left[\frac{p-c+M}{p-c+M-N\left[e^{\theta\left(t_{1}-t_{d}\right)}-1\right]-c_{1} t_{d}}\right] \\
& \quad+\frac{N}{\theta}\left[e^{\theta\left(t_{1}-t_{d}\right)}-\theta\left(t_{1}-t_{d}\right)-1\right]+c_{1} t_{d} t_{1}-\frac{c_{1} t_{d}^{2}}{2}+\frac{A}{D(p)}=0 .
\end{aligned}
$$

Next, to find $t_{1} \in\left[t_{d}, t_{1}^{b}\right)$ which satisfies (4.6), let

$$
\begin{aligned}
& F(x)=\left\{N\left[e^{\theta\left(x-t_{d}\right)}-1\right]+c_{1} t_{d}\right\}\left(\frac{1}{\delta}-x\right)-\frac{(p-c+M)}{\delta} \ln \left[\frac{p-c+M}{p-c+M-N\left[e^{\theta\left(x-t_{d}\right)}-1\right]-c_{1} t_{d}}\right] \\
& +\frac{N}{\theta}\left[e^{\theta\left(x-t_{d}\right)}-\theta\left(x-t_{d}\right)-1\right]+c_{1} t_{d} x-\frac{c_{1} t_{d}^{2}}{2}+\frac{A}{D(p)}, \quad x \in\left[t_{d}, t_{1}^{b}\right) .
\end{aligned}
$$

Taking the first-order derivative of $F(x)$ with respect to $x \in\left(t_{d}, t_{1}^{b}\right)$, it is found that

$$
\frac{d F(x)}{d x}=-\theta N e^{\theta\left(x-t_{d}\right)}\left\{x+\frac{N\left[e^{\theta\left(x-t_{d}\right)}-1\right]+c_{1} t_{d}}{\delta\left\{p-c+M-N\left[e^{\theta\left(x-t_{d}\right)}-1\right]-c_{1} t_{d}\right\}}\right\}<0 .
$$

Thus, $F(x)$ is a strictly decreasing function in $x \in\left[t_{d}, t_{1}^{b}\right)$. Furthermore, it can be shown that $\lim _{x \rightarrow t_{1}^{b^{-}}} F(x)=-\infty$. Now let

$$
\Delta(p) \equiv F\left(t_{d}\right)=\frac{c_{1} t_{d}}{\delta}-\frac{p-c+M}{\delta} \ln \left[\frac{p-c+M}{p-c+M-c_{1} t_{d}}\right]-\frac{c_{1} t_{d}^{2}}{2}+\frac{A}{D(p)}
$$

which gives the following result. 
Lemma 4.1. For any given $p$,

(a) if $\Delta(p) \geq 0$, then the solution of $\left(t_{1}, T\right)$ which satisfies (4.1) not only exists but also is unique,

(b) if $\Delta(p)<0$, then the solution of $\left(t_{1}, T\right)$ which satisfies (4.1) does not exist.

Proof. See Appendix A.

Lemma 4.2. For any given $p$,

(a) if $\Delta(p) \geq 0$, then the total profit per unit time $T P_{1}\left(p, t_{1}, T\right)$ is concave and reaches its global maximum at the point $\left(t_{1}, T\right)=\left(t_{11}, T_{1}\right)$, where $\left(t_{11}, T_{1}\right)$ is the point which satisfies (4.1),

(b) if $\Delta(p)<0$, then the total profit per unit time $T P_{1}\left(p, t_{1}, T\right)$ has a maximum value at the point $\left(t_{1}, T\right)=\left(t_{11}, T_{1}\right)$, where $t_{11}=t_{d}$ and $T_{1}=t_{d}+c_{1} t_{d} /\left(\delta\left(p-c+M-c_{1} t_{d}\right)\right)$.

Proof. See Appendix B.

The problem remaining in Case 1 is to find the optimal value of $p$ which maximizes $T P_{1}\left(p, t_{11}, T_{1}\right)$. Taking the first-and second-order derivatives of $T P_{1}\left(p, t_{11}, T_{1}\right)$ with respect to $p$ gives

$$
\begin{gathered}
\begin{aligned}
\frac{d T P_{1}\left(p, t_{11}, T_{1}\right)}{d p}=\frac{D^{\prime}(p)}{T_{1}}\left\{(p-c+M)\left[t_{11}+\frac{\ln \left[1+\delta\left(T_{1}-t_{11}\right)\right]}{\delta}\right]-\frac{N}{\theta}\left[e^{\theta\left(t_{11}-t_{d}\right)}-\theta\left(t_{11}-t_{d}\right)-1\right]\right. \\
\left.-c_{1} t_{d} t_{11}+\frac{c_{1} t_{d}^{2}}{2}-M T_{1}\right\}+\frac{D(p)}{T_{1}}\left\{t_{11}+\frac{\ln \left[1+\delta\left(T_{1}-t_{11}\right)\right]}{\delta}\right\}
\end{aligned} \\
\begin{aligned}
\frac{d^{2} T P_{1}\left(p, t_{11}, T_{1}\right)}{d p^{2}}=\frac{D^{\prime \prime}(p)}{T_{1}}\left\{(p-c+M)\left[t_{11}+\frac{\ln \left[1+\delta\left(T_{1}-t_{11}\right)\right]}{\delta}\right]-\frac{N}{\theta}\left[e^{\theta\left(t_{11}-t_{d}\right)}-\theta\left(t_{11}-t_{d}\right)-1\right]\right. \\
\left.\quad-c_{1} t_{d} t_{11}+\frac{c_{1} t_{d}^{2}}{2}-M T_{1}\right\}+\frac{2 D^{\prime}(p)}{T_{1}}\left\{t_{11}+\frac{\ln \left[1+\delta\left(T_{1}-t_{11}\right)\right]}{\delta}\right\},
\end{aligned}
\end{gathered}
$$

where $D^{\prime}(p)$ and $D^{\prime \prime}(p)$ are the first-and second-order derivatives of $D(p)$ with respect to $p$, respectively. By the assumptions $D^{\prime}(p)$ and $D^{\prime \prime}(p)<0$, and from (3.20), it is known that the brace term in (4.11) is positive. Therefore $d^{2} T P_{1}\left(p, t_{11}, T_{1}\right) / d p^{2}<0$. Consequently, $T P_{1}\left(p, t_{11}, T_{1}\right)$ is a concave function of $p$ for a given $\left(t_{11}, T_{1}\right)$, and hence there exists a unique value of $p$ (say $\left.p_{1}\right)$ which maximizes $T P_{1}\left(p, t_{11}, T_{1}\right) . p_{1}$ can be obtained by solving $d T P_{1}\left(p, t_{11}, T_{1}\right) / d p=0$; that is, $p_{1}$ can be determined by solving the following equation:

$$
\begin{gathered}
\frac{D^{\prime}(p)}{T_{1}}\left\{(p-c+M)\left[t_{11}+\frac{\ln \left[1+\delta\left(T_{1}-t_{11}\right)\right]}{\delta}\right]-\frac{N}{\theta}\left[e^{\theta\left(t_{11}-t_{d}\right)}-\theta\left(t_{11}-t_{d}\right)-1\right]\right. \\
\left.-c_{1} t_{d} t_{11}+\frac{c_{1} t_{d}^{2}}{2}-M T_{1}\right\}+\frac{D(p)}{T_{1}}\left\{t_{11}+\frac{\ln \left[1+\delta\left(T_{1}-t_{11}\right)\right]}{\delta}\right\}=0 .
\end{gathered}
$$


Case $2\left(t_{1} \leq t_{d}\right)$. Similarly to Case 1 , for any given $p$, the necessary conditions for the total profit per unit time in (3.18) to be maximized are $\partial T P_{2}\left(p, t_{1}, T\right) / \partial t_{1}=0$ and $\partial T P_{2}\left(p, t_{1}, T\right) / \partial T=0$, simultaneously, which implies

$$
\begin{gathered}
(p-c+M) \frac{\delta\left(T-t_{1}\right)}{1+\delta\left(T-t_{1}\right)}-c_{1} t_{1}=0 \\
(p-c+M)\left\{\frac{T}{1+\delta\left(T-t_{1}\right)}-t_{1}-\frac{\ln \left[1+\delta\left(T-t_{1}\right)\right]}{\delta}\right\}+\frac{c_{1} t_{1}^{2}}{2}+\frac{A}{D(p)}=0
\end{gathered}
$$

respectively.

From (4.13), the following is obtained:

$$
T=t_{1}+\frac{c_{1} t_{1}}{\delta\left(p-c+M-c_{1} t_{1}\right)} .
$$

Substituting (4.15) into (4.14) gives

$$
\frac{c_{1} t_{1}}{\delta}-\frac{p-c+M}{\delta} \ln \left[\frac{p-c+M}{p-c+M-c_{1} t_{1}}\right]-\frac{c_{1} t_{1}^{2}}{2}+\frac{A}{D(p)}=0 .
$$

By using a similar approach as used in Case 1, the following results are found.

Lemma 4.3. For any given $p$,

(a) if $\Delta(p) \leq 0$, then the solution of $\left(t_{1}, T\right)$ which satisfies (4.13) and (4.14) not only exists but also is unique,

(b) if $\Delta(p)>0$, then the solution of $\left(t_{1}, T\right)$ which satisfies (4.13) and (4.14) does not exist.

Proof. The proof is similar to Appendix A, and hence is omitted here.

Lemma 4.4. For any given $p$,

(a) if $\Delta(p) \leq 0$, then the total profit per unit time $T P_{2}\left(p, t_{1}, T\right)$ is concave and reaches its global maximum at the point $\left(t_{1}, T\right)=\left(t_{12}, T_{2}\right)$, where $\left(t_{12}, T_{2}\right)$ is the point which satisfies (4.13) and (4.14),

(b) if $\Delta(p)>0$, then the total profit per unit time $T P_{2}\left(p, t_{1}, T\right)$ has a maximum value at the point $\left(t_{1}, T\right)=\left(t_{12}, T_{2}\right)$, where $t_{12}=t_{d}$ and $T_{2}=t_{d}+c_{1} t_{d} /\left(\delta\left(p-c+M-c_{1} t_{d}\right)\right)$.

Proof. The proof is similar to Appendix B, and hence is omitted here.

Likewise, for a given $\left(t_{12}, T_{2}\right)$, taking the first-and second-order derivatives of $T P_{2}\left(p, t_{12}, T_{2}\right)$ in (3.18) with respect to $p$, it is found that

$$
\begin{aligned}
\frac{d T P_{2}\left(p, t_{12}, T_{2}\right)}{d p}= & \frac{D^{\prime}(p)}{T_{2}}\left\{(p-c+M)\left[t_{12}+\frac{\ln \left[1+\delta\left(T_{2}-t_{12}\right)\right]}{\delta}\right]-\frac{c_{1} t_{12}^{2}}{2}-M T_{2}\right\} \\
& +\frac{D(p)}{T_{2}}\left[t_{12}+\frac{\ln \left[1+\delta\left(T_{2}-t_{12}\right)\right]}{\delta}\right]
\end{aligned}
$$




$$
\begin{aligned}
\frac{d^{2} T P_{2}\left(p, t_{12}, T_{2}\right)}{d p^{2}}= & \frac{D^{\prime \prime}(p)}{T_{2}}\left\{(p-c+M)\left[t_{12}+\frac{\ln \left[1+\delta\left(T_{2}-t_{12}\right)\right]}{\delta}\right]-\frac{c_{1} t_{12}^{2}}{2}-M T_{2}\right\} \\
& +\frac{2 D^{\prime}(p)}{T_{2}}\left[t_{12}+\frac{\ln \left[1+\delta\left(T_{2}-t_{12}\right)\right]}{\delta}\right] .
\end{aligned}
$$

It can be shown that $d^{2} T P_{2}\left(p, t_{12}, T_{2}\right) / d p^{2}<0$. Consequently, $T P_{2}\left(p, t_{12}, T_{2}\right)$ is a concave function of $p$ for fixed $\left(t_{12}, T_{2}\right)$, and hence there exists a unique value of $p$ (say $p_{2}$ ) which maximizes $T P_{2}\left(p, t_{12}, T_{2}\right)$. $p_{2}$ can be obtained by solving $d T P_{2}\left(p, t_{12}, T_{2}\right) / d p=0$; that is, $p_{2}$ can be determined by solving the following equation:

$$
\begin{aligned}
& \frac{D^{\prime}(p)}{T_{2}}\left\{(p-c+M)\left[t_{12}+\frac{\ln \left[1+\delta\left(T_{2}-t_{12}\right)\right]}{\delta}\right]-\frac{c_{1} t_{12}^{2}}{2}-M T_{2}\right\} \\
& \quad+\frac{D(p)}{T_{2}}\left[t_{12}+\frac{\ln \left[1+\delta\left(T_{2}-t_{12}\right)\right]}{\delta}\right]=0 .
\end{aligned}
$$

Combining the previous Lemmas 4.2 and 4.4 , the following result is obtained.

Theorem 4.5. For any given $p$,

(a) if $\Delta(p)>0$, the optimal length of time in which there is no inventory shortage is $t_{11}$ and the optimal replenishment cycle length is $T_{1}$,

(b) if $\Delta(p)<0$, the optimal length of time in which there is no inventory shortage is $t_{12}$ and the optimal replenishment cycle length is $T_{2}$,

(c) if $\Delta(p)=0$, the optimal length of time in which there is no inventory shortage is $t_{d}$ and the optimal replenishment cycle length is $t_{d}+\left(c_{1} t_{d} /\left(\delta\left(p-c+M-c_{1} t_{d}\right)\right)\right)$.

Proof. It immediately follows from Lemmas $4.2,4.4$ and the fact that $T P_{1}\left(p, t_{d}, T\right)=$ $T P_{2}\left(p, t_{d}, T\right)$ for given $p$.

Now, the following algorithm is established to obtain the optimal solution $\left(p^{*}, t_{1}^{*}, T^{*}\right)$ of the problem. The convergence of the procedure can be proven by adopting a similar graphical technique as used in Hadley and Whitin [30].

Algorithm 4.6.

Step 1. Start with $j=0$ and the initial value of $p_{j}=c$.

Step 2. Calculate $\Delta\left(p_{j}\right)=\left(c_{1} t_{d} / \delta\right)-\left(\left(p_{j}-c+M\right) / \delta\right) \ln \left[\left(p_{j}-c+M\right) /\left(p_{j}-c+M-c_{1} t_{d}\right)\right]-$ $\left(c_{1} t_{d}^{2} / 2\right)+\left(A / D\left(p_{j}\right)\right)$ for a given $p_{j}$,

(i) if $\Delta\left(p_{j}\right)>0$, determine the values $t_{11, j}$ and $T_{1, j}$ by solving (4.1). Then, put $\left(t_{11, j}, T_{1, j}\right)$ into $(4.12)$ and solve this equation to obtain the corresponding value $p_{1, j+1}$. Let $p_{j+1}=p_{1, j+1}$ and $\left(t_{1 j}, T_{j}\right)=\left(t_{11, j}, T_{1, j}\right)$, go to Step 3 .

(ii) If $\Delta\left(p_{j}\right)<0$, determine the values $t_{12, j}$ and $T_{2, j}$ by solving (4.13) and (4.14). Then, put $\left(t_{12, j}, T_{2, j}\right)$ into (4.19) and solve this equation to obtain the corresponding value $p_{2, j+1}$. Let $p_{j+1}=p_{2, j+1}$ and $\left(t_{1 j}, T_{j}\right)=\left(t_{12, j}, T_{2, j}\right)$, go to Step 3 . 
Table 1: The solution procedure of Example 5.1.

\begin{tabular}{ccccc}
\hline$j$ & $p_{j}$ & $\Delta\left(p_{j}\right)$ & $t_{1, j}$ & $T_{j}$ \\
\hline 1 & 20.0000 & 2.07940 & 1.06971 & 1.45157 \\
2 & 35.6650 & 4.35609 & 1.55179 & 2.03087 \\
3 & 35.9615 & 4.44818 & 1.56773 & 2.05082 \\
4 & 35.9718 & 4.45146 & 1.56829 & 2.05153 \\
5 & 35.9722 & 4.45158 & 1.56831 & 2.05155 \\
\hline
\end{tabular}

(iii) If $\Delta\left(p_{j}\right)=0$, set $t_{1, j}=t_{d}$ and $T_{j}=t_{d}+\left(c_{1} t_{d} / \delta\left(p_{j}-c+M-c_{1} t_{d}\right)\right)$, and then put $\left(t_{1, j}, T_{j}\right)$ into (4.12) or (4.19) to obtain the corresponding value $p_{1, j+1}\left(=p_{2, j+1}\right)$. Let $p_{j+1}=p_{1, j+1}$ or $p_{2, j+1}$ and $\left(t_{1 j}, T_{j}\right)=\left(t_{d}, t_{d}+\left(c_{1} t_{d} /\left(p_{j}-c+M-c_{1} t_{d}\right)\right)\right)$, go to Step 3.

Step 3. If the difference between $p_{j}$ and $p_{j+1}$ is enough small (i.e., $\left|p_{j}-p_{j+1}\right| \leq 10^{-5}$ ), then set $p^{*}=p_{j}$ and $\left(t_{1}^{*}, T^{*}\right)=\left(t_{1 j}, T_{j}\right)$. Thus $\left(p^{*}, t_{1}^{*}, T^{*}\right)$ is the optimal solution. Otherwise, set $j=j+1$ and go back to Step 2 .

The previous algorithm can be implemented with the help of a computer-oriented numerical technique for a given set of parameter values. Once $\left(p^{*}, t_{1}^{*}, T^{*}\right)$ is obtained, $Q^{*}$ can be found from (3.10) or (3.17) and $T P^{*}=T P\left(p^{*}, t_{1}^{*}, T^{*}\right)$ from (3.16) or (3.18).

\section{Numerical Examples}

In order to illustrate the solution procedure for this inventory system, the following examples are presented.

Example 5.1. This example is based on the following cost parameter values: $A=\$ 250 /$ per order, $c=\$ 20 /$ per unit, $c_{1}=\$ 1 /$ per unit/per unit time, $c_{2}=\$ 5 /$ per unit/per unit time, $c_{3}=\$ 25 /$ per unit, $\theta=0.08, t_{d}=1 / 12$, and $B(x)=1 /(1+0.1 x)$. In addition, it is assumed that the demand rate is a linearly decreasing function of the selling price and is given by $D(p)=200-4 p$, where $0<p<50$. Under the given values of the parameters and according to the algorithm in the previous section, the computational results can be found as shown in Table 1. From Table 1, it can be seen that after five iterations, the optimal selling price $p^{*}=\$ 35.9722$, the optimal length of time in which there is no inventory shortage $t_{1}^{*}=1.56831$, and the optimal length of replenishment cycle $T^{*}=2.05155$. Hence the optimal order quantity $Q^{*}=119.632$ units, and the optimal total profit per unit time of the inventory system $T P\left(p^{*}, t_{1}^{*}, T^{*}\right)=\$ 660.918$.

Moreover, if $t_{d}=0$, this model becomes the instantaneous deterioration case, and the optimal solutions can be found as follows: $p^{*}=36.0234, t_{1}{ }^{*}=1.5556, T^{*}=2.05227, Q^{*}=$ 119.711, and $T P^{*}=655.022$. The results with instantaneous and non instantaneous deterioration models for $t_{d} \in\{1 / 12,2 / 12,3 / 12\}$ are shown in Table 2. From Table 2, it can be seen that there is an improvement in total profit from the non-instantaneously deteriorating demand model. Moreover, the longer the length of time where no deterioration occurs, the greater the improvement in total profit will be. This implies that if the retailer can extend the length of time in which no deterioration occurs by improving stock equipment, then the total profit per unit time will increase. 
Table 2: The results with instantaneous and non-instantaneous deterioration models.

\begin{tabular}{lccccr}
\hline$t_{d}$ & $p^{*}$ & $t_{1}^{*}$ & $T^{*}$ & $Q^{*}$ & $T P^{*}$ \\
\hline 0 & 36.0234 & 1.5556 & 2.05227 & 119.711 & 655.022 \\
(i.e., instantaneous deterioration case) & & & & & \\
$1 / 12$ & 35.9722 & 1.56831 & 2.05155 & 119.632 & 660.918 \\
$2 / 12$ & 35.9246 & 1.58283 & 2.05327 & 119.690 & 666.569 \\
$3 / 12$ & 35.4801 & 1.59914 & 2.05744 & 119.888 & 671.973 \\
\hline
\end{tabular}

Table 3: Sensitivity analysis with respect to the cost items.

\begin{tabular}{|c|c|c|c|c|c|c|}
\hline Parameter & $\%$ change & $p^{*}$ & $t_{1}^{*}$ & $\begin{array}{c}T^{*} \\
\% \text { change }\end{array}$ & $Q^{*}$ & $T P^{*}$ \\
\hline \multirow{4}{*}{$A$} & -50 & -0.85 & -28.79 & -29.50 & -28.83 & 10.82 \\
\hline & -25 & -0.39 & -13.15 & -13.53 & -13.14 & 4.94 \\
\hline & 25 & 0.35 & 11.56 & 11.98 & 11.51 & -4.35 \\
\hline & 50 & 0.67 & 22.00 & 22.85 & 21.86 & -8.28 \\
\hline \multirow{4}{*}{$c$} & -50 & -14.57 & 6.21 & -2.32 & 35.49 & 105.25 \\
\hline & -25 & -7.31 & 1.63 & -2.61 & 16.15 & 48.36 \\
\hline & 25 & 7.41 & 1.31 & 5.93 & -14.48 & -39.87 \\
\hline & 50 & 15.01 & 6.61 & 16.94 & -28.48 & -71.19 \\
\hline \multirow{4}{*}{$c_{1}$} & -50 & -0.23 & 12.87 & 7.79 & 9.51 & 2.90 \\
\hline & -25 & -0.11 & 5.95 & 3.57 & 4.34 & 1.38 \\
\hline & 25 & 0.10 & -5.19 & -3.06 & -3.71 & -1.27 \\
\hline & 50 & 0.20 & -9.78 & -5.72 & -6.91 & -2.45 \\
\hline \multirow{4}{*}{$c_{2}$} & -50 & -0.19 & -4.14 & 4.81 & 4.34 & 1.53 \\
\hline & -25 & -0.08 & -1.79 & 2.03 & 1.83 & 0.66 \\
\hline & 25 & 0.06 & 1.42 & -1.55 & -1.40 & -0.52 \\
\hline & 50 & 0.11 & 2.56 & -2.78 & -2.51 & -0.95 \\
\hline \multirow{4}{*}{$c_{3}$} & -50 & -0.08 & -1.79 & 2.03 & 1.83 & 0.66 \\
\hline & -25 & -0.04 & -0.84 & 0.94 & 0.85 & 0.31 \\
\hline & 25 & 0.03 & 0.75 & -0.83 & -0.75 & -0.28 \\
\hline & 50 & 0.06 & 1.42 & -1.55 & -1.40 & -0.52 \\
\hline \multirow{4}{*}{$\theta$} & -50 & -0.31 & 25.70 & 16.32 & 15.89 & 4.75 \\
\hline & -25 & -0.14 & 11.06 & 6.91 & 6.81 & 2.19 \\
\hline & 25 & 0.12 & -8.72 & -5.32 & -5.32 & -1.90 \\
\hline & 50 & 0.23 & -15.82 & -9.54 & -9.62 & -3.57 \\
\hline
\end{tabular}

Example 5.2. This study now investigates the effects of changes in the values of the cost parameters $A, c, c_{1}, c_{2}, c_{3}$, and $\theta$ on the optimal selling price $p^{*}$, the optimal length of time in which there is no inventory shortage $t_{1}^{*}$, the optimal length of replenishment cycle $T^{*}$, the optimal order quantity $Q^{*}$, and the optimal total profit per unit time of inventory system $\operatorname{TP}\left(p^{*}, t_{1}^{*}, T^{*}\right)$ according to Example 5.1. For convenience, only the case with a linear demand function $D(p)=400-4 p$, where $0<p<100$, is considered. The sensitivity analysis is performed by changing each value of the parameters by $+50 \%,+25 \%,-25 \%$, and $-50 \%$, taking one parameter at a time and keeping the remaining parameter values unchanged. The computational results are shown in Table 3. 
On the basis of the results of Table 3, the following observations can be made.

(a) The optimal selling price $p^{*}$ increases with an increase in the values of parameters $A, c, c_{1}, c_{2}, c_{3}$, and $\theta$. Moreover, $p^{*}$ is weakly positively sensitive to changes in parameters $A, c_{1}, c_{2}, c_{3}$, and $\theta$, whereas $p^{*}$ is highly positively sensitive to changes in parameter $c$. It is reasonable that the purchase cost has a strong and positive effect upon the optimal selling price.

(b) The optimal length of time in which there is no inventory shortage $t_{1}^{*}$ increases with increased values of parameters $A, c_{2}$, and $c_{3}$ while it decreases as the values of parameters $c_{1}$ and $\theta$ increase. From an economic viewpoint, this means that the retailer will avoid shortages when the order cost, shortage cost, and cost of lost sales are high.

(c) The optimal length of the replenishment cycle $T^{*}$ increases with an increase in the value of parameter $A$, while it decreases as the values of parameters $c_{1}, c_{2}, c_{3}$, and $\theta$ increase. This implies that the higher the order cost the longer the length of the replenishment cycle, while the lower the holding cost, shortage cost, cost of lost sales, and deteriorating rate, the longer the length of the replenishment cycle.

(d) The optimal order quantity $Q^{*}$ increases with an increase in the value of parameter $A$ and decreases with an increase in the values of parameters $c, c_{1}, c_{2}, c_{3}$, and $\theta$. The corresponding managerial insight is that as the order cost increases, the order quantity increases. On the other hand, as the purchasing cost, holding cost, shortage cost, cost of lost sales, and deterioration rate increase, the order quantity decreases.

(e) The optimal total profit per unit time $T P^{*}$ decreases with an increase in the values of parameters $A, c, c_{1}, c_{2}, c_{3}$, and $\theta$. This implies that increases in costs and the deterioration rate have a negative effect upon the total profit per unit time.

\section{Conclusions}

The problem of determining the optimal replenishment policy for non-instantaneous deteriorating items with price-dependent demand is considered in this study. A model is developed in which shortages are allowed and the backlogging rate is variable and dependent on the waiting time for the next replenishment. There are two possible scenarios in this study: (1) the length of time in which there is no shortage is larger than or equal to the length of time in which the product exhibits no deterioration (i.e., $t_{1} \geq t_{d}$ ) and (2) the length of time in which there is no shortage is shorter than or equal to the length of time in which the product exhibits no deterioration $\left(t_{1} \leq t_{d}\right)$. Through theoretical analysis several useful theorems are developed and an algorithm is provided to determine the optimal selling price, the optimal length of time in which there is no inventory shortage, and the optimal replenishment cycle time for various situations. Several numerical examples are provided to illustrate the theoretical results under various situations and a sensitivity analysis of the optimal solution with respect to major parameters is also carried out. This paper contributes to existing methodology in several ways. Firstly, it addresses the problem of noninstantaneous deteriorating items under the circumstances in which the demand rate is price sensitive and there is partial backlogging, hitherto not treated in the literature. Secondly, it develops several useful theoretical results and provides an algorithm to determine the optimal selling price and length of replenishment cycle. Finally, from the theoretical results, it can be seen that the retailer may determine the optimal order quantity and selling price by 
considering whether to sell his/her stocks before or after the products begin to deteriorate in the case of non-instantaneous deteriorating items.

In the future it is hoped that the model will be further developed to incorporate other realistic circumstances such as capital investment in storehouse equipment to reduce the deterioration rate of items, stochastic demand, and a finite replenishment rate.

\section{Appendices}

\section{A. Proof of Lemma 4.1}

Proof of Part (a). It can be seen that $\mathrm{F}(\mathrm{x})$ is a strictly decreasing function in $x \in\left[t_{d}, t_{1}^{b}\right)$ and $\lim _{x \rightarrow t_{1}^{b^{-}}} F(x)=-\infty$. Therefore, if $\Delta(p) \equiv F\left(t_{d}\right) \geq 0$, then by using the Intermediate Value Theorem, there exists a unique value of $t_{1}$ (say $t_{11}$ ) such that $F\left(t_{11}\right)=0$; that is, $t_{11}$ is the unique solution of (4.4). Once the value $t_{11}$ is found, then the value of $T$ (denoted by $T_{1}$ ) can be found from (4.3) and is given by $T_{1}=t_{11}+\left(\left(N\left[e^{\theta\left(t_{11}-t_{d}\right)}-1\right]+c_{1} t_{d}\right) / \delta\left\{p-c+M-N\left[e^{\theta\left(t_{11}-t_{d}\right)}-\right.\right.\right.$ $\left.\left.1]-c_{1} t_{d}\right\}\right)$.

Proof of Part (b). If $\Delta(p) \equiv F\left(t_{d}\right)<0$, then from $F(x)$ is a strictly decreasing function of $x \in$ $\left[t_{d}, t_{1}^{b}\right)$, which implies $F(x)<0$ for all $x \in\left[t_{d}, t_{1}^{b}\right)$. Thus, a value $t_{1} \in\left[t_{d}, t_{1}^{b}\right)$ cannot be found such that $F\left(t_{1}\right)=0$. This completes the proof.

\section{B. Proof of Lemma 4.2}

Proof of Part (a). For any given $p$, taking the second derivatives of $T P_{1}\left(t_{1}, T, p\right)$ with respect to $t_{1}$ and $T$ and then finding the values of these functions at point $\left(t_{1}, T\right)=\left(t_{11}, T_{1}\right)$ give

$$
\begin{aligned}
& \left.\frac{\partial^{2} T P_{1}\left(p, t_{1}, T\right)}{\partial t_{1}^{2}}\right|_{\left(t_{11}, T_{1}\right)}=\frac{D(p)}{T_{1}}\left\{\frac{-\delta(p-c+M)}{\left[1+\delta\left(T_{1}-t_{11}\right)\right]^{2}}-N e^{\theta\left(t_{11}-t_{d}\right)}\right\}<0, \\
& \left.\frac{\partial^{2} T P_{1}\left(p, t_{1}, T\right)}{\partial T^{2}}\right|_{\left(t_{11}, T_{1}\right)}=\frac{D(p)}{T_{1}}\left\{\frac{-\delta(p-c+M)}{\left[1+\delta\left(T_{1}-t_{11}\right)\right]^{2}}\right\}<0, \\
& \left.\frac{\partial^{2} T P_{1}\left(p, t_{1}, T\right)}{\partial t_{1} \partial T}\right|_{\left(t_{11}, T_{1}\right)}=\frac{D(p)}{T_{1}}\left\{\frac{\delta(p-c+M)}{\left[1+\delta\left(T_{1}-t_{11}\right)\right]^{2}}\right\}, \\
& \left.\frac{\partial^{2} T P_{1}\left(p, t_{1}, T\right)}{\partial t_{1}^{2}}\right|_{\left(t_{11}, T_{1}\right)} \times\left.\frac{\partial^{2} T P_{1}\left(p, t_{1}, T\right)}{\partial T^{2}}\right|_{\left(t_{11}, T_{1}\right)}-\left[\left.\frac{\partial^{2} T P_{1}\left(p, t_{1}, T\right)}{\partial t_{1} \partial T}\right|_{\left(t_{11}, T_{1}\right)}\right]^{2} \\
& =\left(\frac{D(p)}{T_{1}}\right)^{2}\left\{\frac{\delta(p-c+M) N e^{\theta\left(t_{11}-t_{d}\right)}}{\left[1+\delta\left(T_{1}-t_{11}\right)\right]^{4}}\right\}>0 .
\end{aligned}
$$

Because $\left(t_{11}, T_{1}\right)$ is the unique solution of $(4.1)$ if $\Delta(p) \geq 0$, therefore, for any given $p,\left(t_{11}, T_{1}\right)$ is the global maximum point of $T P_{1}\left(t_{1}, T, p\right)$. 
Proof of Part (b). For any given $p$, if $\Delta(p)<0$, then it is known that $F(x)<0$, for all $x \in\left[t_{d}, t_{1}^{b}\right)$. Thus,

$$
\begin{aligned}
\frac{d T P_{1}\left(p, t_{1}, T\right)}{d T}=\frac{D(p)}{T^{2}} \times\{ & -\left\{N\left[e^{\theta\left(t_{1}-t_{d}\right)}-1\right]+c_{1} t_{d}\right\} t_{1}+\frac{N\left[e^{\theta\left(t_{1}-t_{d}\right)}-1\right]+c_{1} t_{d}}{\delta} \\
& -\frac{(p-c+M)}{\delta} \ln \left[\frac{p-c+M}{p-c+M-N\left[e^{\theta\left(t_{1}-t_{d}\right)}-1\right]-c_{1} t_{d}}\right] \\
& \left.+\frac{N}{\theta}\left[e^{\theta\left(t_{1}-t_{d}\right)}-\theta\left(t_{1}-t_{d}\right)-1\right]+c_{1} t_{d} t_{1}-\frac{c_{1} t_{d}^{2}}{2}+\frac{A}{D(p)}\right\} \\
= & \frac{D(p) F\left(t_{1}\right)}{T^{2}}<0, \quad \forall t_{1} \in\left[t_{d}, t_{1}^{b}\right),
\end{aligned}
$$

which implies that $T P_{1}\left(t_{1}, T, p\right)$ is a strictly decreasing function of $T$. Thus, $T P_{1}\left(t_{1}, T, p\right)$ has a maximum value when $T$ is minimum. On the other hand, from (4.3), it can be seen that $T$ has a minimum value of $t_{d}+\left(c_{1} t_{d} /\left(\delta\left(p-c+M-c_{1} t_{d}\right)\right)\right)$ as $t_{1}=t_{d}$. Therefore, $T P_{1}\left(t_{1}, T, p\right)$ has a maximum value at the point $\left(t_{11}, T_{1}\right)$, where $t_{11}=t_{d}$ and $T_{1}=t_{d}+\left(c_{1} t_{d} /\left(\delta\left(p-c+M-c_{1} t_{d}\right)\right)\right)$. This completes the proof.

\section{Acknowledgment}

The authors greatly appreciate the anonymous referees for their valuable and helpful suggestions regarding earlier version of the paper.

\section{References}

[1] F. W. Harris, "How many parts to make at once," Factory, The Magazine of Management, vol. 10, no. 2, pp. 135-136, 1913.

[2] P. M. Ghare and G. H. Schrader, "A model for an exponentially decaying inventory," Journal of Industrial Engineering, vol. 14, pp. 238-243, 1963.

[3] R. P. Covert and G. C. Philip, "An EOQ model with Weibull distribution deterioration," AIIE Transactions, vol. 5, no. 4, pp. 323-326, 1973.

[4] G. C. Philip, "A generalized EOQ model for items with Weibull distribution," AIIE Transactions, vol. 6, no. 2, pp. 159-162, 1974

[5] P. R. Tadikamalla, "An EOQ inventory model for items with Gamma distribution," AIIE Transactions, vol. 10, no. 4, pp. 100-103, 1978.

[6] Y. K. Shah, "An order-level lot size inventory model for deteriorating items," AIIE Transactions, vol. 9, no. 1, pp. 108-112, 1977.

[7] K. S. Park, "Inventory models with partial backorders," International Journal of Systems Science, vol. 13, no. 2, pp. 1313-1317, 1982.

[8] H. M. Wee, "Perishable commodities inventory policy with partial backordering," Chung Yuan Journal, vol. 12, pp. 191-198, 1992.

[9] P. L. Abad, "Optimal pricing and lot sizing under conditions of perishability and partial backordering," Management Science, vol. 42, no. 8, pp. 1093-1104, 1996.

[10] P. L. Abad, "Optimal price and order size for a reseller under partial backordering," Computers $\mathcal{E}$ Operations Research, vol. 28, no. 1, pp. 53-65, 2001.

[11] C. Y. Dye, "Joint pricing and ordering policy for a deteriorating inventory with partial backlogging," Omega, vol. 35, no. 2, pp. 184-189, 2007. 
[12] S. K. Goyal, "Economic ordering policy for deteriorating items over an infinite time horizon," European Journal of Operational Research, vol. 28, no. 3, pp. 298-301, 1987.

[13] K. V. S. Sarma, "Deterministic order level inventory model for deteriorating items with two storage facilities," European Journal of Operational Research, vol. 29, no. 1, pp. 70-73, 1987.

[14] F. Raafat, P. M. Wolfe, and H. K. Eldin, "Inventory model for deteriorating items," Computers and Industrial Engineering, vol. 20, no. 1, pp. 89-104, 1991.

[15] T. P. M. Pakkala and K. K. Achary, "Deterministic inventory model for deteriorating items with two warehouses and finite replenishment rate," European Journal of Operational Research, vol. 57, no. 1, pp. 71-76, 1992.

[16] S. K. Goyal and B. C. Giri, "Recent trends in modeling of deteriorating inventory," European Journal of Operational Research, vol. 134, no. 1, pp. 1-16, 2001.

[17] L. Y. Ouyang, K. S. Wu, and C. T. Yang, "A study on an inventory model for non-instantaneous deteriorating items with permissible delay in payments," Computers $\mathcal{E}$ Industrial Engineering, vol. 51, no. 4, pp. 637-651, 2006.

[18] C. Y. Dye, L. Y. Ouyang, and T. P. Hsieh, "Deterministic inventory model for deteriorating items with capacity constraint and time-proportional backlogging rate," European Journal of Operational Research, vol. 178, no. 3, pp. 789-807, 2007.

[19] K. S. Wu, L. Y. Ouyang, and C. T. Yang, "An optimal replenishment policy for non-instantaneous deteriorating items with stock-dependent demand and partial backlogging," International Journal of Production Economics, vol. 101, no. 2, pp. 369-384, 2006.

[20] S. Eilon and R. V. Mallaya, "Issuing and pricing policy of semi-perishables," in Proceedings of the 4th International Conference on Operational Research, Wiley-Interscience, New York, NY, USA, 1966.

[21] M. A. Cohen, "Joint pricing and ordering policy for exponentially decaying inventory with known demand," Naval Research Logistics Quarterly, vol. 24, no. 2, pp. 257-268, 1977.

[22] H. M. Wee, "Joint pricing and replenishment policy for deteriorating inventory with declining market," International Journal of Production Economics, vol. 40, pp. 163-171, 1995.

[23] H. M. Wee, "A replenishment policy for items with a price-dependent demand and a varying rate of deterioration," Production Planning E Control, vol. 8, no. 5, pp. 494-499, 1997.

[24] H. M. Wee, "Deteriorating inventory model with quantity discount, pricing and partial backordering," International Journal of Production Economics, vol. 59, no. 1, pp. 511-518, 1999.

[25] H. M. Wee and S. T. Law, "Replenishment and pricing policy for deteriorating items taking into account the time value of money," International Journal of Production Economics, vol. 71, pp. 213-220, 2001.

[26] P. L. Abad, "Optimal pricing and lot-sizing under conditions of perishability, finite production and partial backordering and lost sale," European Journal of Operational Research, vol. 144, no. 3, pp. 677$685,2003$.

[27] S. Mukhopadhyay, R. N. Mukherjee, and K. S. Chaudhuri, "Joint pricing and ordering policy for a deteriorating inventory," Computers and Industrial Engineering, vol. 47, pp. 339-349, 2004.

[28] S. Mukhopadhyay, R. N. Mukherjee, and K. S. Chaudhuri, "An EOQ model with two-parameter Weibull distribution deterioration and price-dependent demand," International Journal of Mathematical Education in Science and Technology, vol. 36, no. 1, pp. 25-33, 2005.

[29] H. J. Chang, J. T. Teng, L. Y. Ouyang, and C. Y. Dye, “Retailer's optimal pricing and lot-sizing policies for deteriorating items with partial backlogging," European Journal of Operational Research, vol. 168, no. 1, pp. 51-64, 2006.

[30] G. Hadley and T. Whitin, Analysis of Inventory Systems, Prentice-Hall, Englewood Cliff, NJ, USA, 1963. 


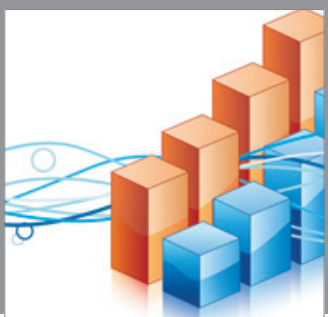

Advances in

Operations Research

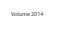

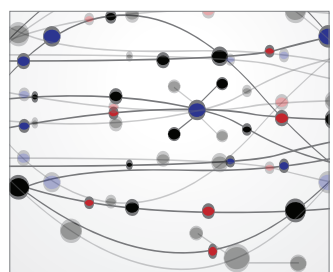

\section{The Scientific} World Journal
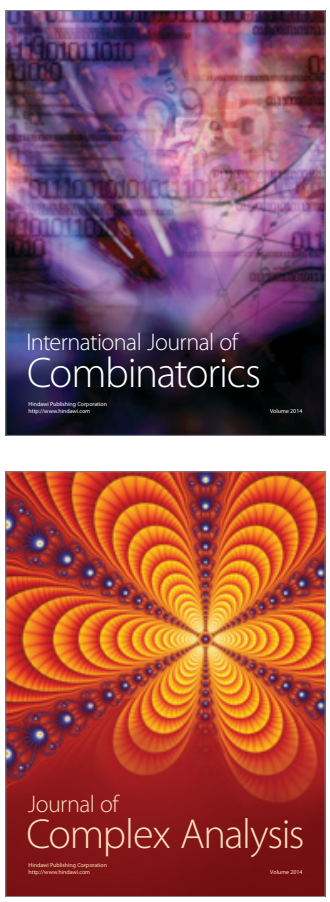

International Journal of

Mathematics and

Mathematical

Sciences
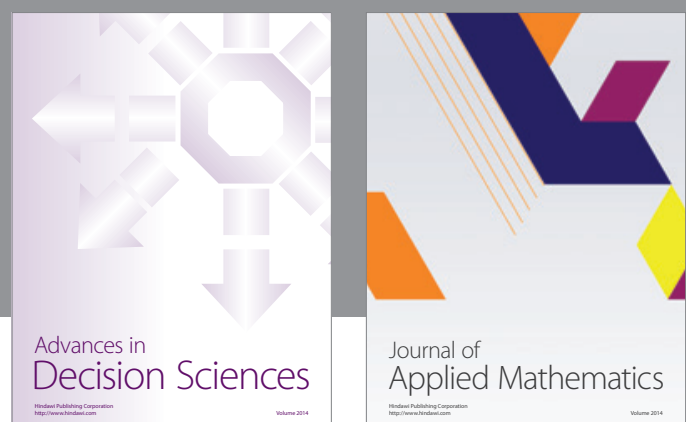

Journal of

Applied Mathematics
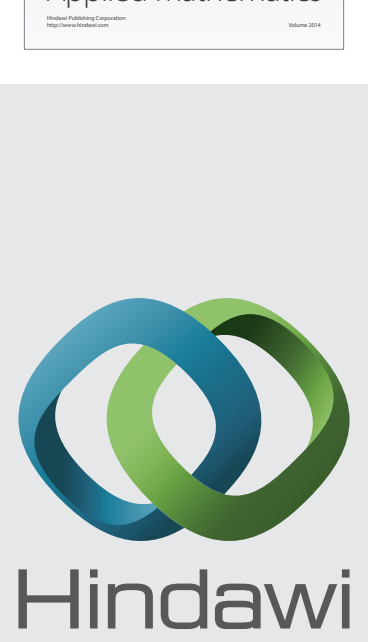

Submit your manuscripts at http://www.hindawi.com
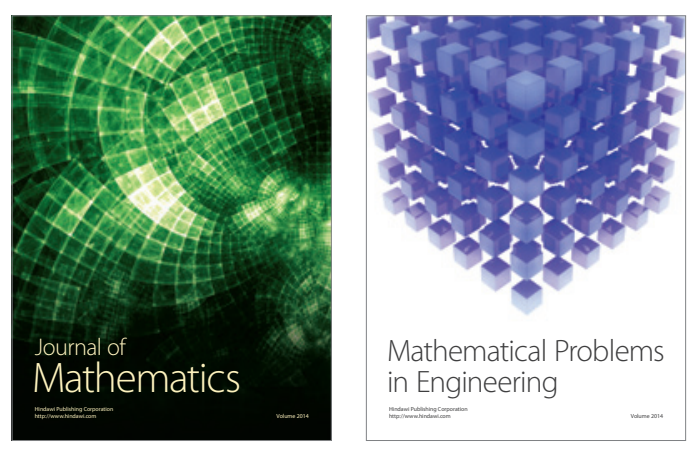

Mathematical Problems in Engineering
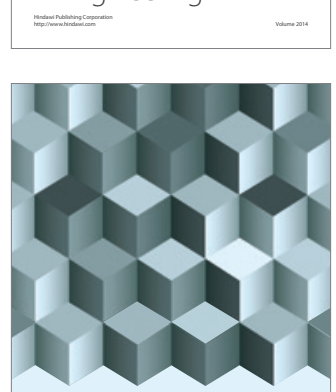

Journal of

Function Spaces
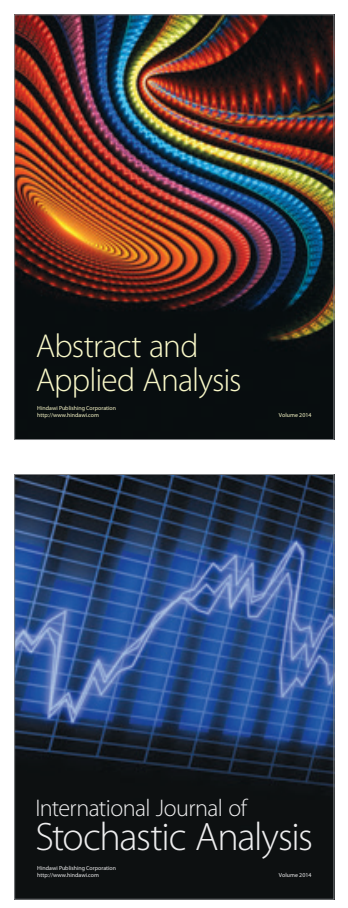

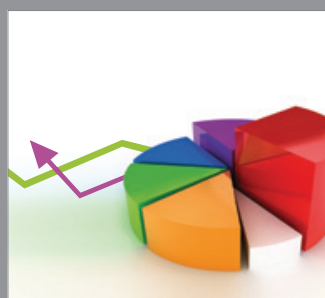

ournal of

Probability and Statistics

Promensencen
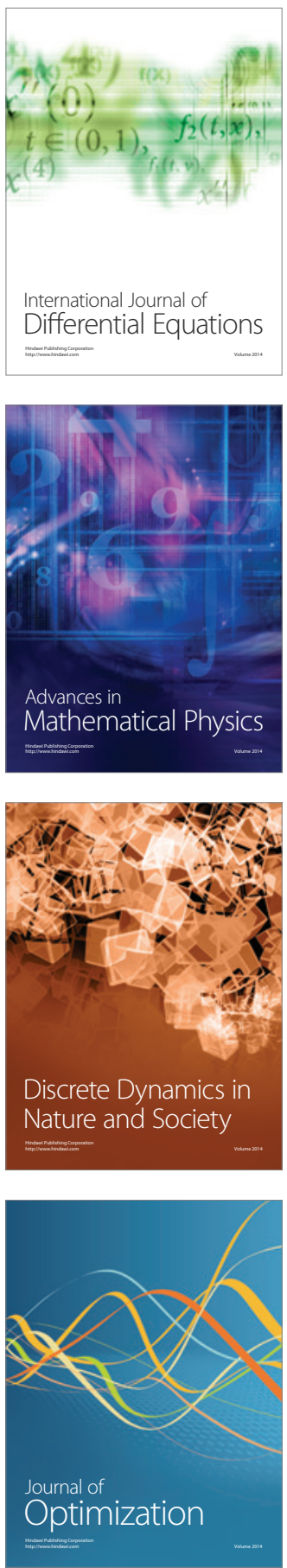